\title{
The mechanism of the enzymatic fluorination in Streptomyces cattleya
}

Xiaofeng Zhu, David A. Robinson, Andrew R. McEwan, David O'Hagan* \& James H Naismith* Center for Biomolecular Sciences, University of St. Andrews, St Andrews, KY16 9ST

*Correspondence to

James H Naismith Tel: +44(0)1334463792 Fax: +44(0)1334 467229 Email: naismith@ st-and.ac.uk

David O’Hagan Tel: +44(0)1334467176 Fax: +44(0)1334 463808 Email: do1 @ st-and.ac.uk 
Table S1 The binding affinities of ligands towards FDAS and mutants by isothermal titration calorimetry. $\mathrm{N}$ is the stoichiometry, $\mathrm{Ka}$ is association constant $(\times 105), \Delta \mathrm{H}$ the enthalpy of binding $(\times 103 \mathrm{kJmol}-1), \Delta \mathrm{S}$ is the entropy change (kJmol-1). The data for apo wild type FDAS are repeated from Table 1 . The data for the mutant T80A and S158G binding with SAM only are shown. The presence of residual SAM in these mutants will interfere with the analysis of other ligands.

\begin{tabular}{|l|l|l|l|l|l|l|l|l|l|l|l|l|}
\hline & \multicolumn{9}{l}{ SAM } & \multicolumn{9}{l|}{ SAH } & \multicolumn{3}{l|}{ FDA } \\
\hline & $\mathrm{N}$ & $\mathrm{K}_{\mathrm{a}}$ & $\Delta \mathrm{H}$ & $\Delta \mathrm{S}$ & $\mathrm{N}$ & $\mathrm{K}_{\mathrm{a}}$ & $\Delta \mathrm{H}$ & $\Delta \mathrm{S}$ & $\mathrm{N}$ & $\mathrm{K}_{\mathrm{a}}$ & $\Delta \mathrm{H}$ & $\Delta \mathrm{S}$ \\
\hline WT & $0.56 \pm 0.01$ & $8.0 \pm 0.5$ & $-25.4 \pm 0.4$ & -58 & $0.72 \pm 0.005$ & $302 \pm 74$ & $-39.6 \pm 0.5$ & -98 & $1.2 \pm 0.01$ & $45.5 \pm 6.5$ & $-14 \pm 0.1$ & -17. \\
\hline T80S & $0.44 \pm 0.01$ & $5.8 \pm 0.3$ & $-29 \pm 0.6$ & -71 & $0.74 \pm 0.01$ & $33.4 \pm 5.1$ & $-37.4 \pm 0.6$ & -96 & $0.96 \pm 0.01$ & $16.9 \pm 1.5$ & $-14.4 \pm 0.2$ & -20 \\
\hline S158A & $0.41 \pm 0.01$ & $4.8 \pm 0.2$ & $-30 \pm 0.6$ & -74 & $0.74 \pm 0.01$ & $34.8 \pm 7.0$ & $-42.5 \pm 0.9$ & -113 & $0.81 \pm 0.01$ & $12.1 \pm 0.9$ & $-18.9 \pm 0.2$ & -35. \\
\hline T80A & $0.36 \pm 0.02$ & $5.4 \pm 0.5$ & $-26.6 \pm 1.4$ & -63 & & & & & & & & \\
\hline S158G & $0.20 \pm 0.01$ & $4.0 \pm 0.4$ & $-26.8 \pm 2.1$ & -64 & & & & & & & & \\
\hline
\end{tabular}


Table S2 Crystallography statistics for the structures

\begin{tabular}{|c|c|c|c|c|c|c|}
\hline & Apo FDAS & $\begin{array}{l}\mathrm{S} 158 \mathrm{G}+\mathrm{Cl}^{-} \\
+\mathrm{SAM}\end{array}$ & $\begin{array}{l}\mathrm{S} 158 \mathrm{G}+\mathrm{Cl}^{-} \\
+\mathrm{SAH}\end{array}$ & $\begin{array}{l}\text { S158A+FDA } \\
\text { +Met }\end{array}$ & $\begin{array}{l}\text { WT FDAS } \\
+ \text { FDA }\end{array}$ & $\begin{array}{l}\text { S158G } \\
\text { FDA }\end{array}$ \\
\hline \multicolumn{7}{|l|}{ Data collection } \\
\hline Space group & $\mathrm{P} 2{ }_{1} 2_{1} 2_{1}$ & $\mathrm{C} 2221$ & $\mathrm{C} 2221$ & $\mathrm{C} 2221$ & $\mathrm{C} 2221$ & $\mathrm{C} 2221$ \\
\hline Cell dimensions & & & $\alpha=\beta=\gamma=90$ & & & \\
\hline$a, b, c(\AA)$ & $\begin{array}{l}a=103.70 \\
b=127.96 \\
c=146.45\end{array}$ & $\begin{array}{l}a=76.22 \\
b=129.38 \\
c=183.08\end{array}$ & $\begin{array}{l}a=76.28 \\
b=127.81 \\
c=182.80\end{array}$ & $\begin{array}{l}a=74.58 \\
b=127.36 \\
c=180.19\end{array}$ & $\begin{array}{l}a=75.89 \\
b=129.95 \\
c=184.49\end{array}$ & $\begin{array}{l}a=75.85 \\
b=129.26 \\
c=184.48\end{array}$ \\
\hline$\alpha, \beta, \gamma\left({ }^{\circ}\right)$ & $\alpha=\beta=\gamma=90$ & $\alpha=\beta=\gamma=90$ & $\alpha=\beta=\gamma=90$ & $\alpha=\beta=\gamma=90$ & $\alpha=\beta=\gamma=90$ & $\alpha=\beta=\gamma=90$ \\
\hline Resolution $(\AA)$ & $54.2-2.6$ & $30-2.0$ & $37.2-2.1$ & $34.4-2.0$ & $37.2-1.9$ & $53.4-1.9$ \\
\hline$R_{\text {sym }}$ or $R_{\text {merge }}$ & $0.096(0.418)$ & $0.079(0.362)$ & $0.066(0.419)$ & $0.050(0.331)$ & $\begin{array}{l}0.053 \\
(0.252)\end{array}$ & $0.08(0.393)$ \\
\hline$I / \sigma I$ & $13.6(3.3)$ & $17.8(3.3)$ & $18.7(2.4)$ & $28.3(4.2)$ & $25.0(6.0)$ & $15.7(4.0)$ \\
\hline Completeness (\%) & $99.5(99.9)$ & 96 (98.6) & $97.0(89.6)$ & $82.2(83.0)$ & $95.5(90.3)$ & $99.0(96.5)$ \\
\hline Redundancy & $3.6(3.6)$ & $4.9(4.6)$ & $4.3(4.2)$ & $5.1(4.5)$ & $5.2(5.0)$ & $6.7(5.7)$ \\
\hline \multicolumn{7}{|l|}{ Refinement } \\
\hline Resolution $(\AA)$ & $96.2-2.6$ & $30-2.0$ & $36.9-2.1$ & $35.2-2.0$ & $37.2-1.9$ & $53.4-1.9$ \\
\hline No. reflections & 57084 & 55867 & 45152 & 47782 & 61281 & 67279 \\
\hline$R_{\text {work }} / R_{\text {free }}$ & $0.220 / 0.304$ & $0.164 / 0.204$ & $0.171 / 0.212$ & $0.189 / 0.229$ & $0.180 / 0.221$ & 0.1870 .221 \\
\hline \multicolumn{7}{|l|}{ No. atoms } \\
\hline Protein & 13320 & 6678 & 6654 & 6657 & 6712 & 6659 \\
\hline Ligand/ion & 30 & $81 / 3$ & $78 / 3$ & 84 & 57 & 57 \\
\hline Water & 406 & 791 & 452 & 623 & 783 & 736 \\
\hline \multicolumn{7}{|l|}{$B$-factors } \\
\hline Protein & 28.4 & 21.4 & 29.6 & 25.4 & 25.9 & 24.8 \\
\hline Ligand/ion & 36 & $20 / 33$ & $24 / 30$ & 25 & 18 & 18 \\
\hline Water & 28 & 33 & 35 & 34 & 37 & 38 \\
\hline \multicolumn{7}{|l|}{ R.m.s deviations } \\
\hline Bond lengths ( $(\AA)$ & 0.019 & 0.013 & 0.014 & 0.012 & 0.013 & 0.013 \\
\hline Bond angles $\left({ }^{\circ}\right)$ & 1.89 & 1.35 & 1.43 & 1.42 & 1.41 & 1.39 \\
\hline PDB Code & $2 \mathrm{c} 4 \mathrm{u}$ & $2 \mathrm{v} 7 \mathrm{u}$ & $2 \mathrm{v} 7 \mathrm{t}$ & $2 \mathrm{v} 7 \mathrm{x}$ & $2 \mathrm{v} 7 \mathrm{v}$ & $2 \mathrm{v} 7 \mathrm{w}$ \\
\hline
\end{tabular}


Table S3 Primers used to generate the mutations in FDAS*

\begin{tabular}{|c|c|}
\hline Mutant & Primers \\
\hline \multirow[t]{2}{*}{ D16A } & 5'-GCGTTCATGAGCGCCCTGGGGACCA-3' \\
\hline & 5'-TGGTCCCCAGGGCGCTCATGAACGC-3' \\
\hline \multirow[t]{2}{*}{ D16S } & 5'-GCGTTCATGAGCTCCCTGGGGACCACG-3' \\
\hline & 5'-CGTGGTCCCCAGGGAGCTCATGAACGC-3' \\
\hline \multirow[t]{2}{*}{ D16N } & 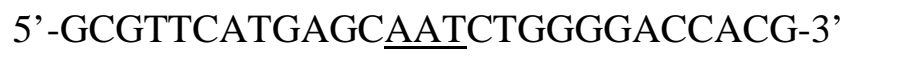 \\
\hline & 5'-CTGGGTCCCCAGATTGCTCATGAACGC-3' \\
\hline \multirow[t]{2}{*}{ T80A } & 5'-CCTATCCGGCGGCCGGCACCACCA-3' \\
\hline & 5'-TGGTGGTGCCGGCCGCCGGATAGG-3' \\
\hline \multirow[t]{2}{*}{$\mathrm{T} 80 \mathrm{~S}$} & 5'-CCTATCCGGCGTCCGGCACCACC-3' \\
\hline & 5'-GGTGGTGCCGGACGCCGGATAGG-3' \\
\hline \multirow[t]{2}{*}{ F156A } & 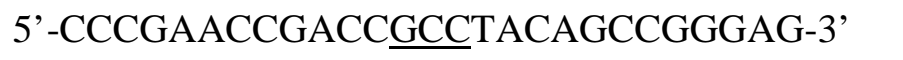 \\
\hline & 5'-CTCCCGGCTGTAGGCGGTCGGTTCGGG-3' \\
\hline \multirow[t]{2}{*}{ F156V } & 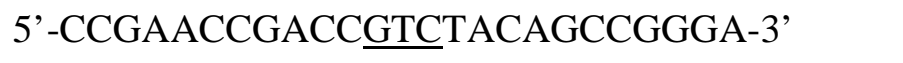 \\
\hline & 5'-TCCCGGCTGTAGACGGTCGGTTCGG-3' \\
\hline \multirow[t]{2}{*}{ S158A } & 5'-ACCGACCTTCTACGCCCGGGAGATGGTGG-3' \\
\hline & 5'-CCACCATCTCCCGGGCGTAGAAGGTCGGT-3' \\
\hline \multirow[t]{2}{*}{ S158G } & 5'-CCGACCTTCTACGGCCGGGAGATGGT-3' \\
\hline & 5'-ACCATCTCCCGGCCGTAGAAGGTCGGTT-3' \\
\hline
\end{tabular}

*The underlined bases represent the mutated codons, which at least change two bases of the codon. 
Supporting Information

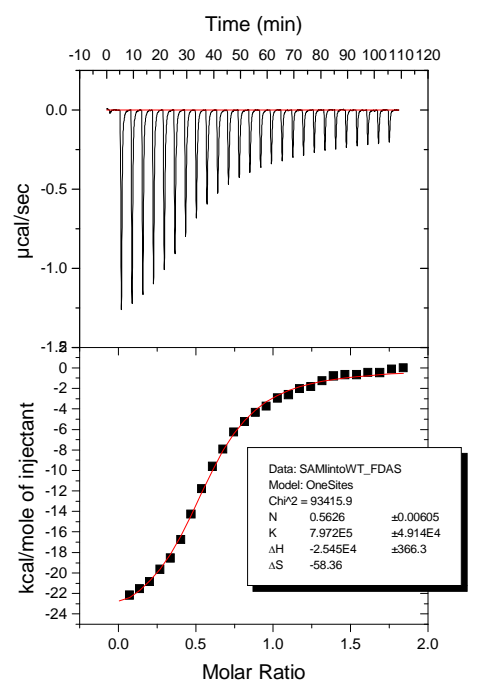

a SAM

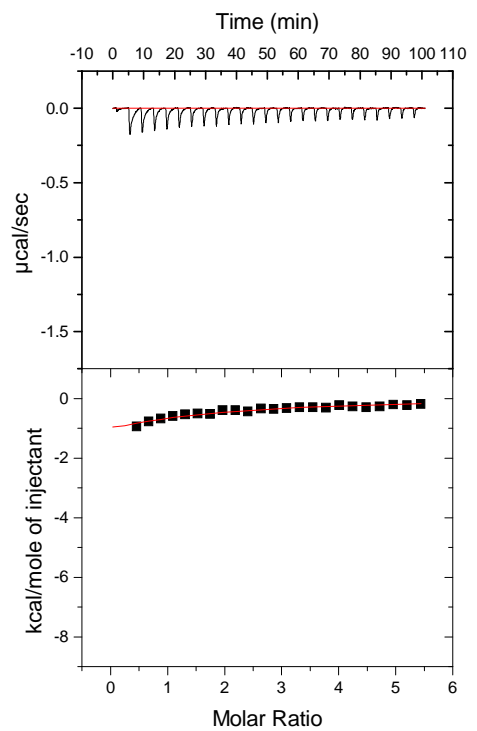

d L-Met

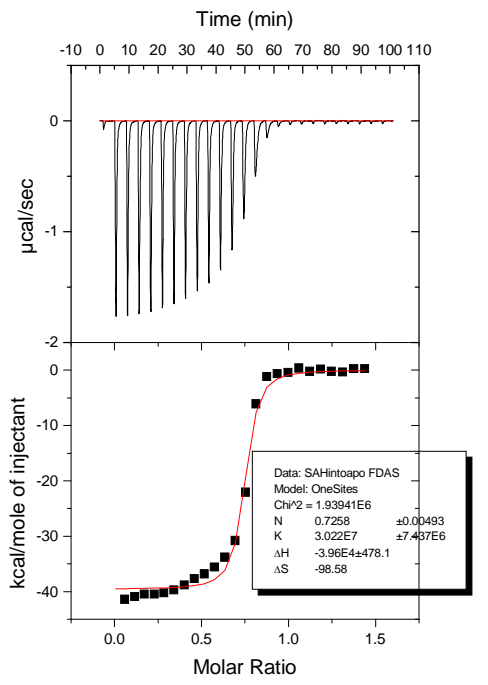

b SAH

Time ( $\mathrm{min})$

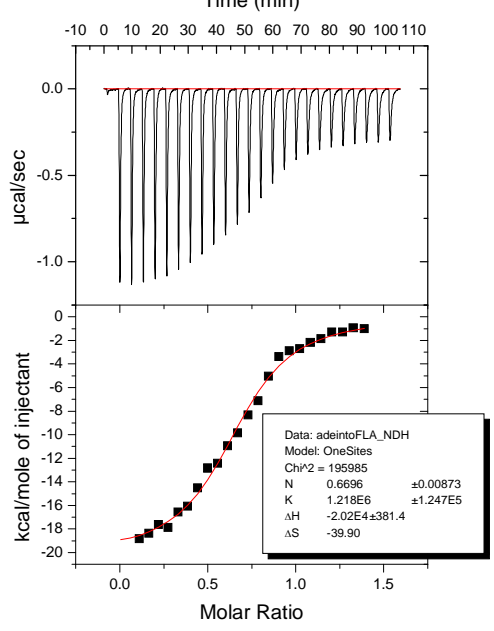

e Adenosine
Mechanism of fluorination

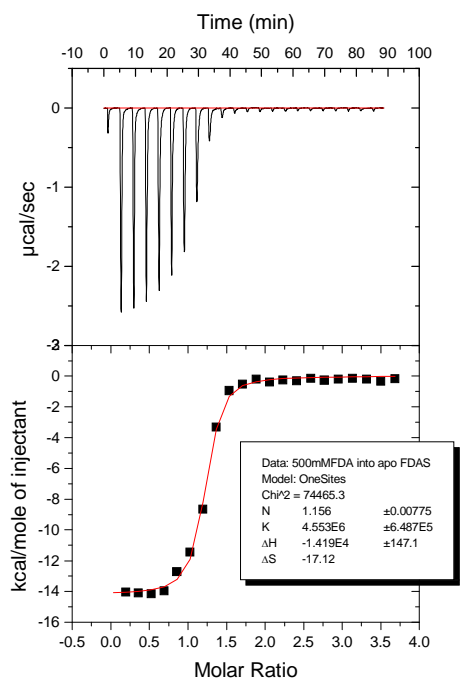

\section{c FDA}

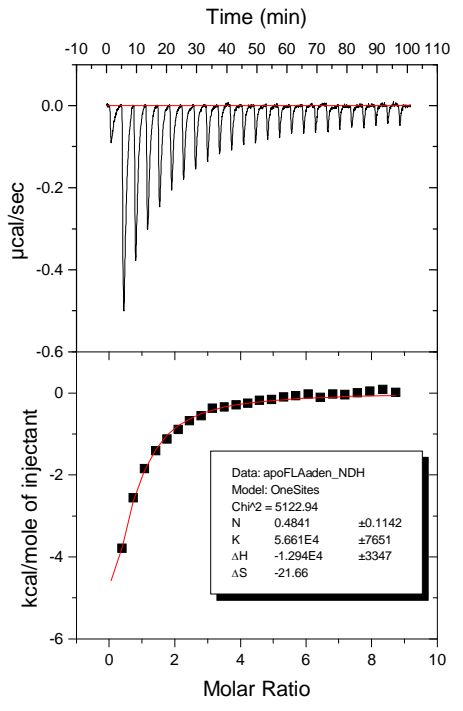

f L-Met after mixing FDAS with adenosine 
Supporting Information

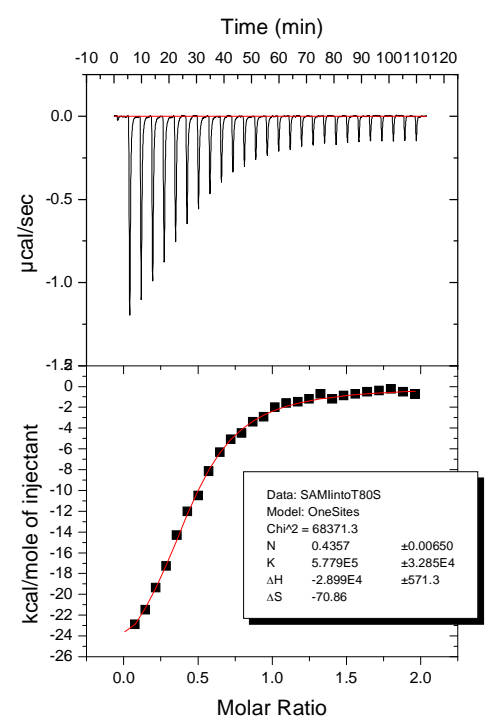

g SAM into T80S

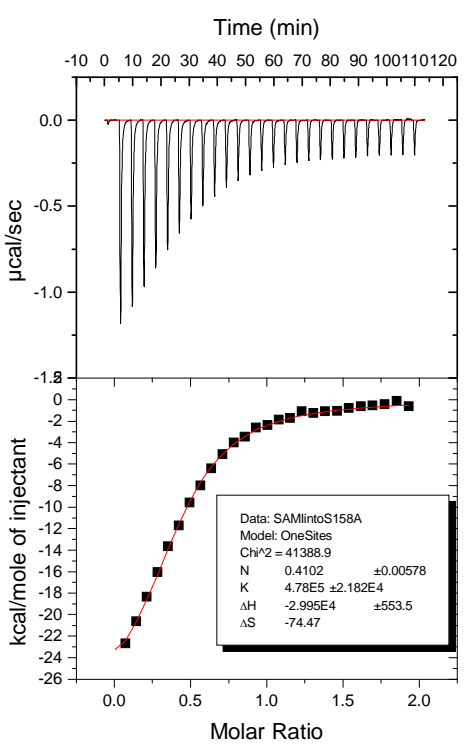

j SAM into S158A

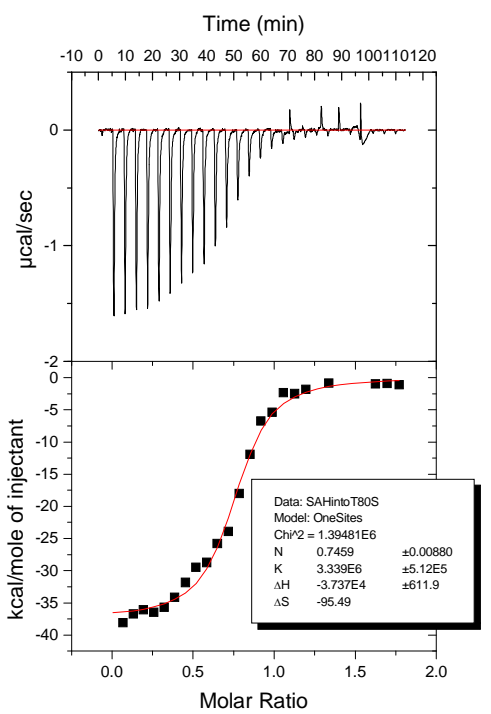

h SAH into T80S

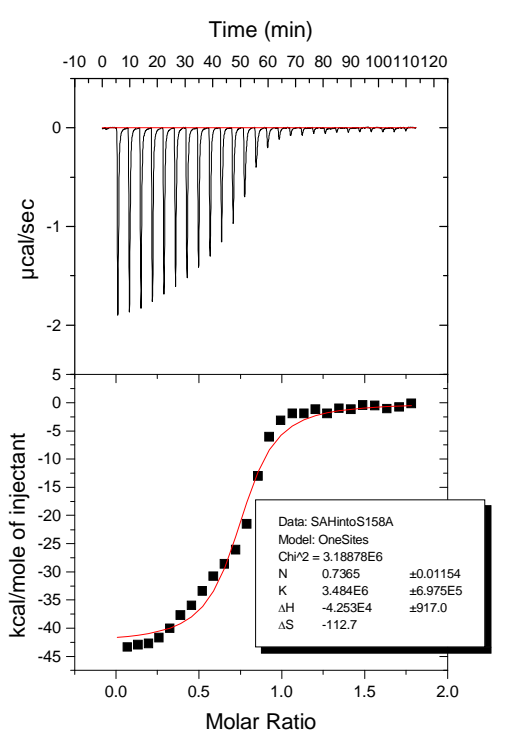

k SAH into S158A
Mechanism of fluorination

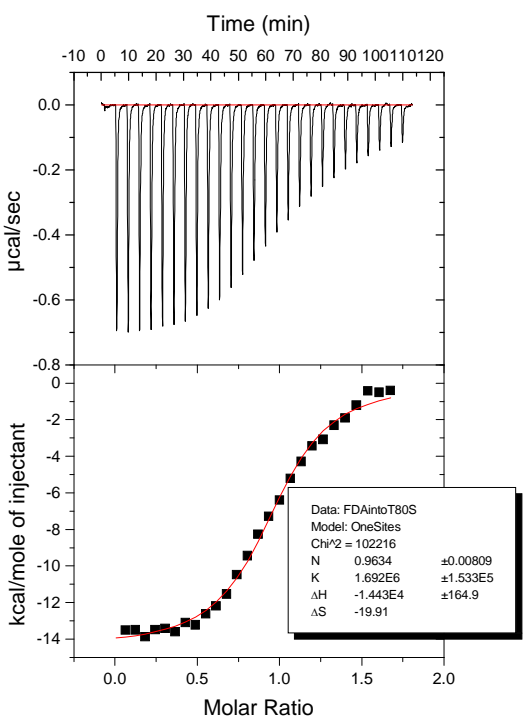

i FDA into T80S

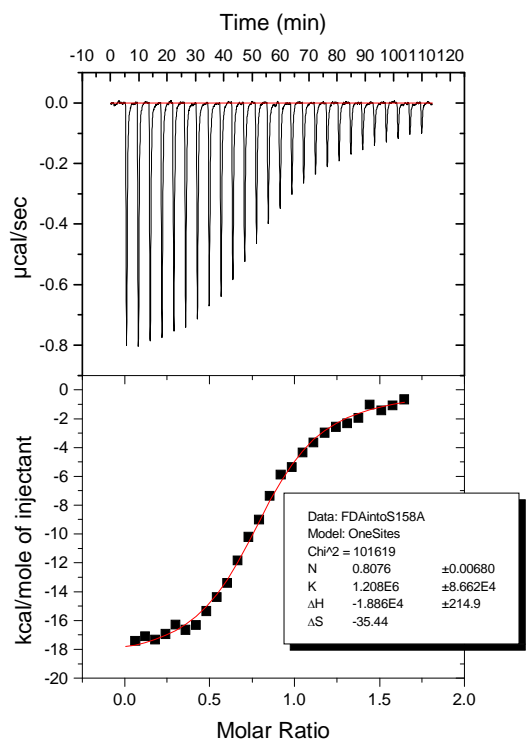

1 FDA into S158A 


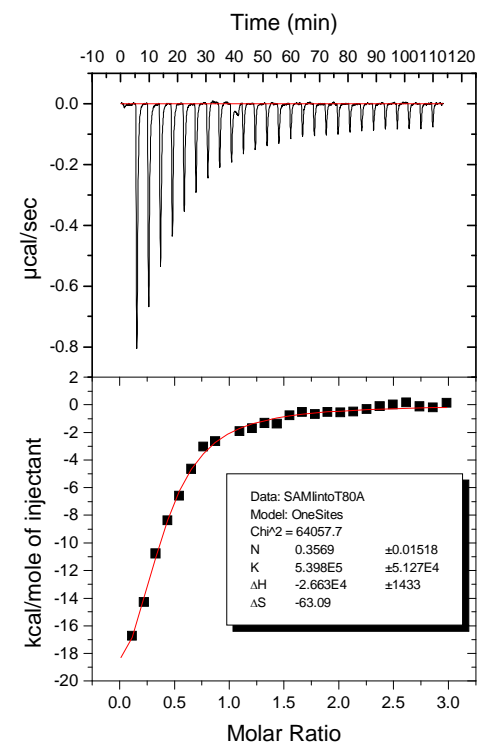

m SAM into T80A

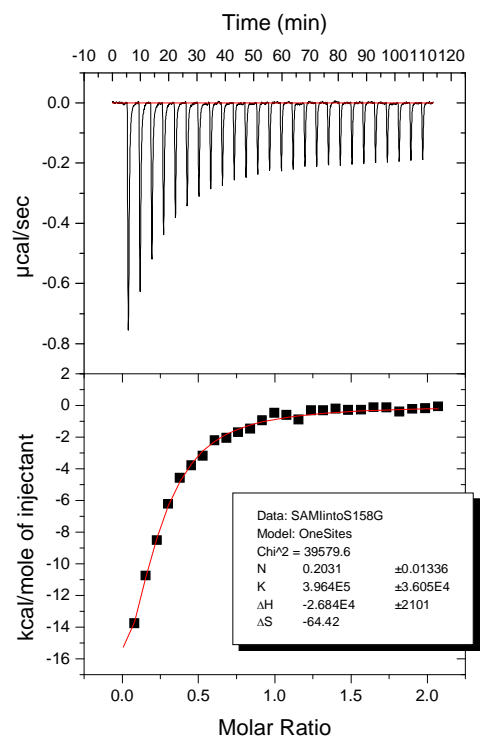

n SAM into S158G

Figure S1: ITC determination of the binding affinity of ligands towards FDAS or the mutants. the data are summarized in table 1 and table S2. (a) titration of $0.174 \mathrm{mM}$ SAM into $0.02 \mathrm{mM}$ FDAS; (b) titration of $0.154 \mathrm{mM}$ SAH into $0.02 \mathrm{mM}$ FDAS; (c) titration of $0.549 \mathrm{mM}$ FDA into $0.02 \mathrm{mM}$ FDAS; (d) titration of 1mM L-methionine into $0.02 \mathrm{mM}$ FDAS; (e) titration of $0.137 \mathrm{mM}$ adenosine into $0.018 \mathrm{mM}$ FDAS; (f) titration of $1 \mathrm{mM}$ L-methionine into $0.024 \mathrm{mM}$ Adenosine and $0.02 \mathrm{mM}$ apo FDAS mixture; $(\mathrm{g}$ ) titration of SAM into T80S; (h) titration of SAH into T80S; (i) titration of FDA into T80S; (j) titration of SAM into S158A; (k) titration of SAH into S158A; (1) titration of FDA into S158A; (m) titration of SAM into T80A; (n) titration of SAM into S158G 


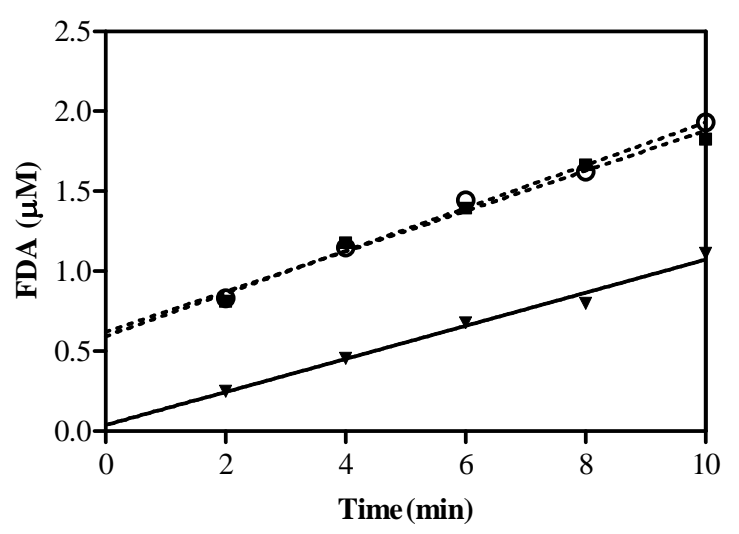

Figure S2 Active site titration of FDAS complexes: [FDAS-F-] ( $\mathbf{\square})$, [FDAS-SAM] ( $\mathbf{\nabla})$ and [FDAS] (O), in which the titrations were initialized by the remaining reaction component such as SAM, F, or SAM and $\mathrm{F}^{-}$ respectively in $20 \mathrm{mM}$ sodium phosphate buffer $(\mathrm{pH} 7.8)$. All titrations were performed at the constant concentrations of FDAS $(2 \mu \mathrm{M})$ and $\mathrm{F}^{-}(100 \mathrm{mM})$ with $100 \mu \mathrm{M}$ SAM.

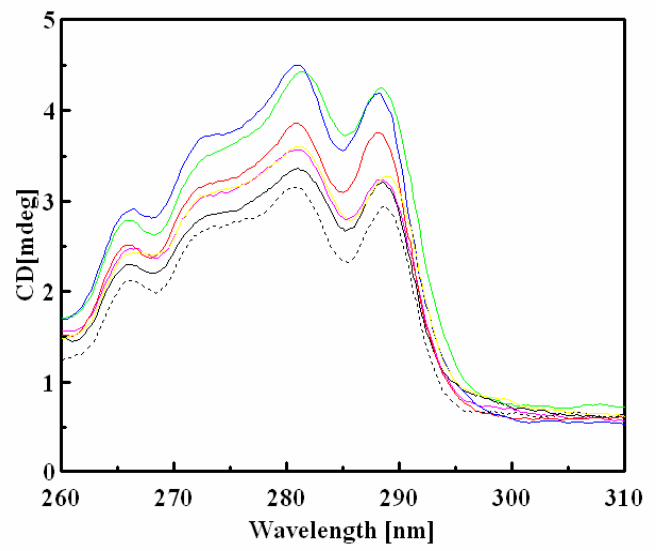

b

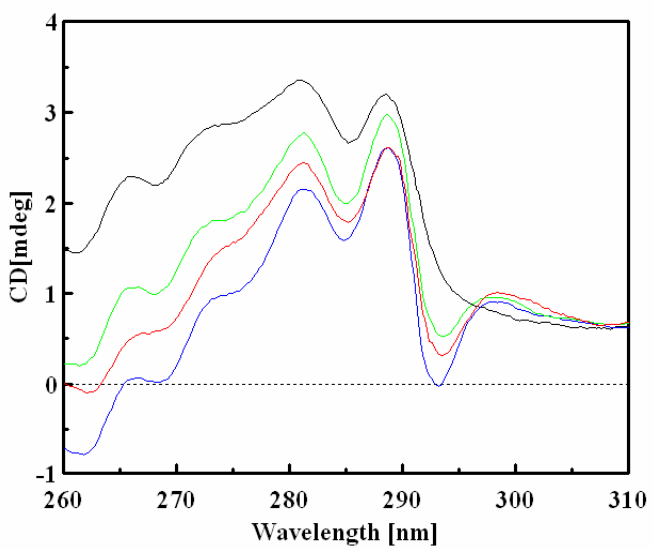

Figure S3 The near UV CD spectra of mutants. panel a includes the near UV CD spectra T80S (magenta), T80A (yellow), S158A (black dot), D16A (red), D16N (green) and D16S (blue); panel b includes the near UV CD spectra for F156V (green), F156A (blue) and S158G (red). The near UV CD spectrum of wild type FDAS is shown in both panels for comparison (black). 

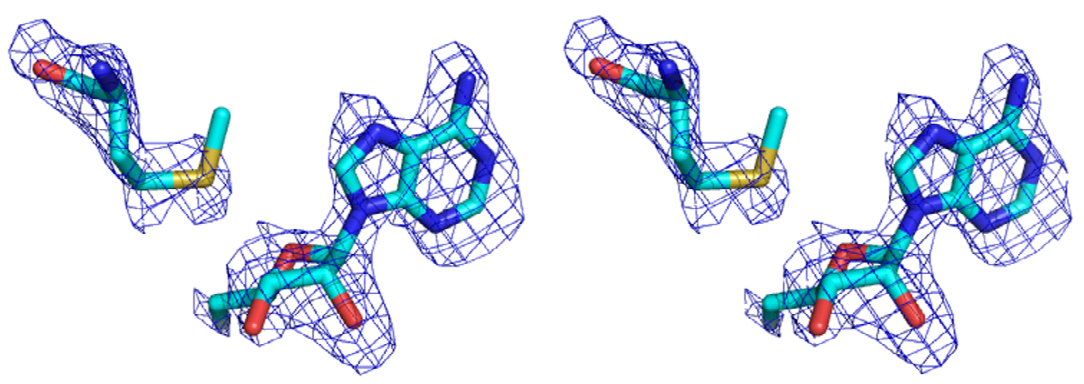

a S158A ternary complex with FDA and L-Met
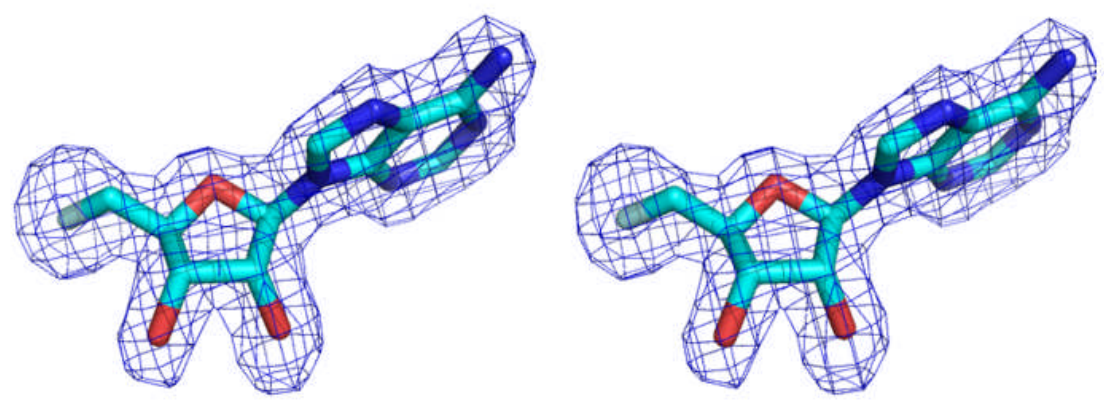

b FDAS binary complex with FDA
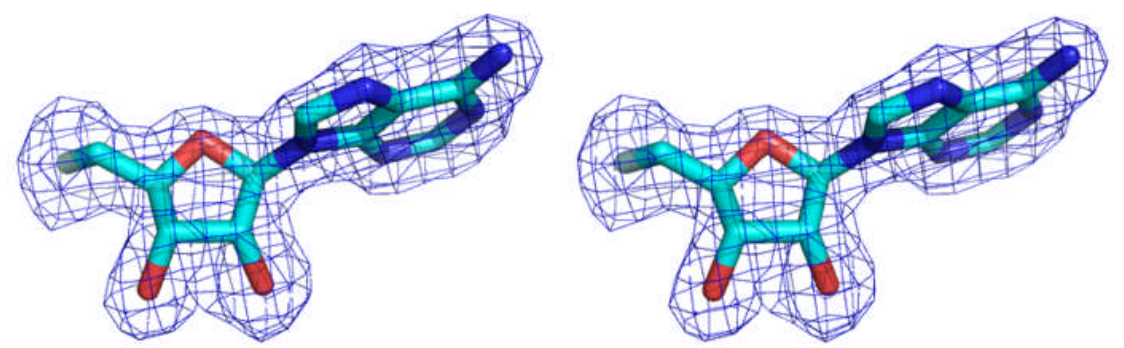

c S158G binary complex with FDA 

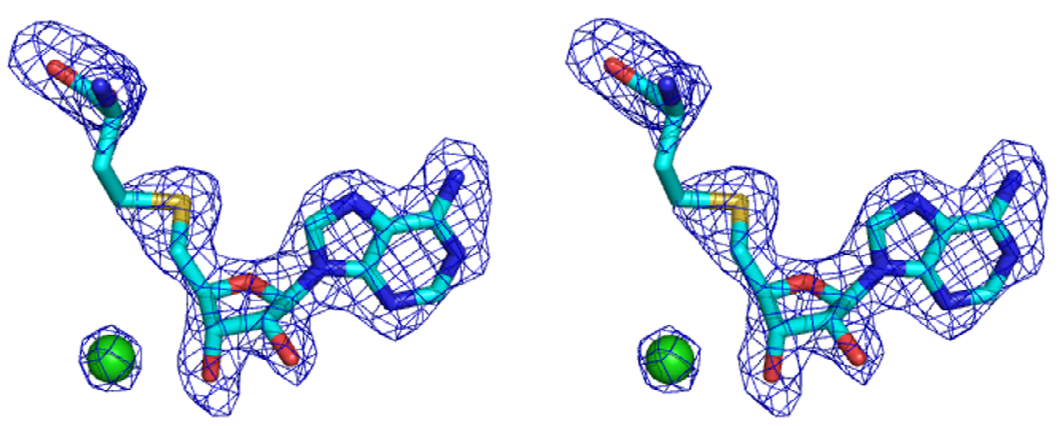

d S158G ternary complex with $\mathrm{SAH}$ and $\mathrm{Cl}^{-}$
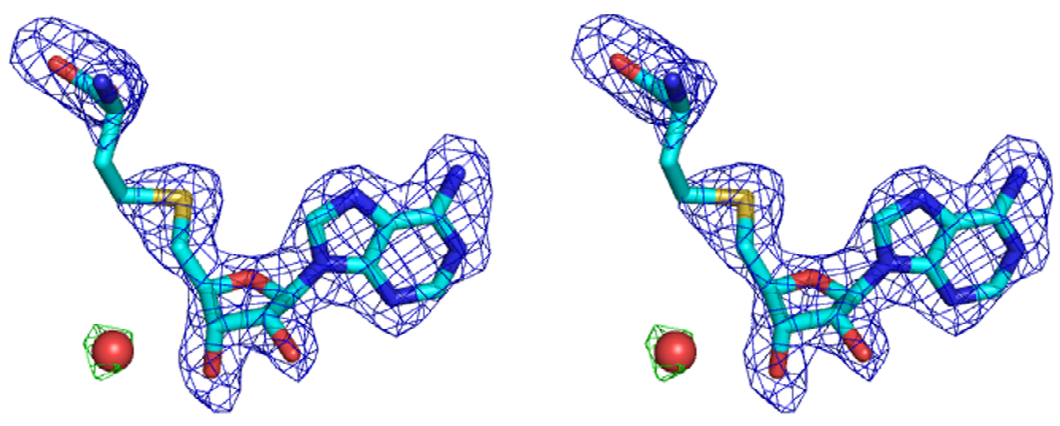

e S158G ternary complex with $\mathrm{SAH}$ and $\mathrm{Cl}^{-}$
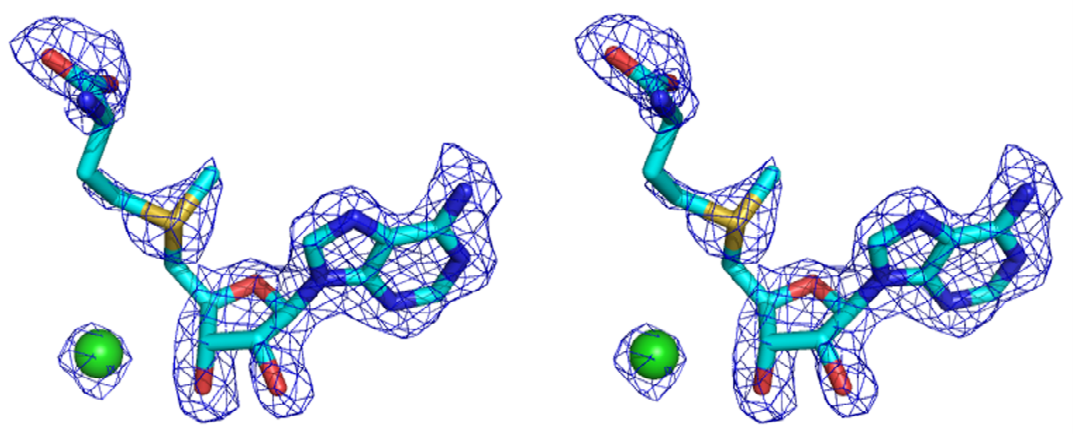

f S158G ternary complex with SAM and $\mathrm{Cl}^{-}$ 

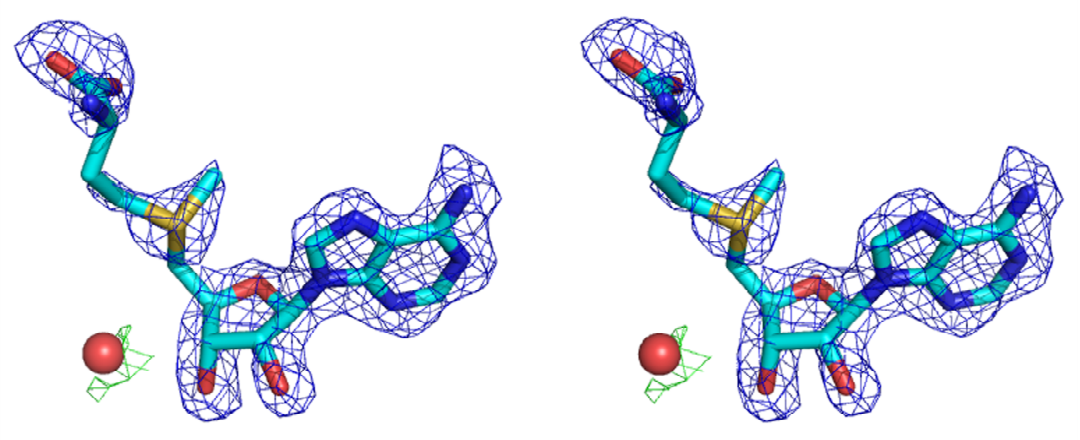

g S158G ternary complex with SAM and $\mathrm{Cl}^{-}$

Figure S4 The unbiased Fo-Fc map contoured at $3 \sigma$ in blue (otherwise indicated) for all ligands in the related structures. The maps were calculated with phase based on a model which never included the ligands. The final refined ligands are shown. (a) S158A complex with FDA and L-Met; (b) wild type FDAS complex with FDA; (c) S158G complex with FDA; (d) S158G complex with SAH and $\mathrm{Cl}^{-}$, the unbiased Fo-Fc map contoured at 3 $\sigma$ around SAH and at $9 \sigma$ around $\mathrm{Cl}^{-}$. The map is calculated with phase based on a model which never included $\mathrm{SAH}$ and $\mathrm{Cl}^{-}$; (e) Fo-Fc map contoured at $3 \sigma$ around the water molecule after refinement of a water molecule at the position of $\mathrm{Cl}^{-}$; (f) $\mathrm{S} 158 \mathrm{G}$ complex with SAM and $\mathrm{Cl}^{-}$, the unbiased Fo-Fc map contoured at $3 \sigma$ around SAM and at $6 \sigma$ around $\mathrm{Cl}^{-}$. The map is calculated with phase based on a model which never included SAM and $\mathrm{Cl}^{-}$; (g) Fo-Fc map contoured at $3 \sigma$ around the water molecule after refinement of a water molecule at the position of $\mathrm{Cl}^{-}$. 

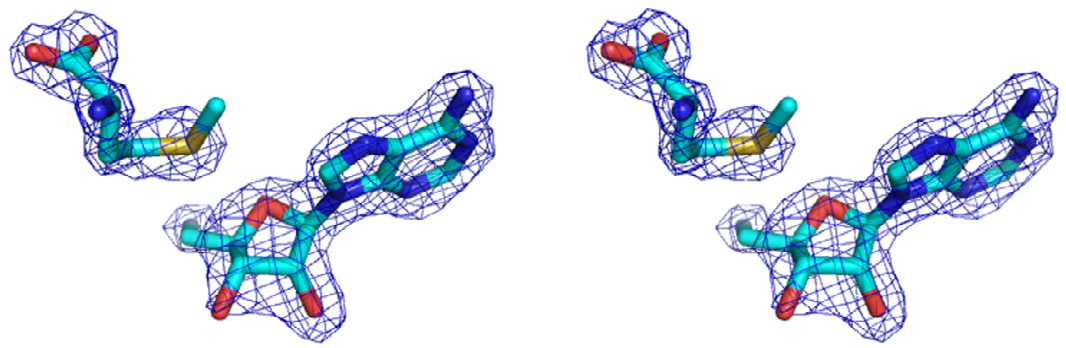

a S158A ternary complex with FDA and L-Met
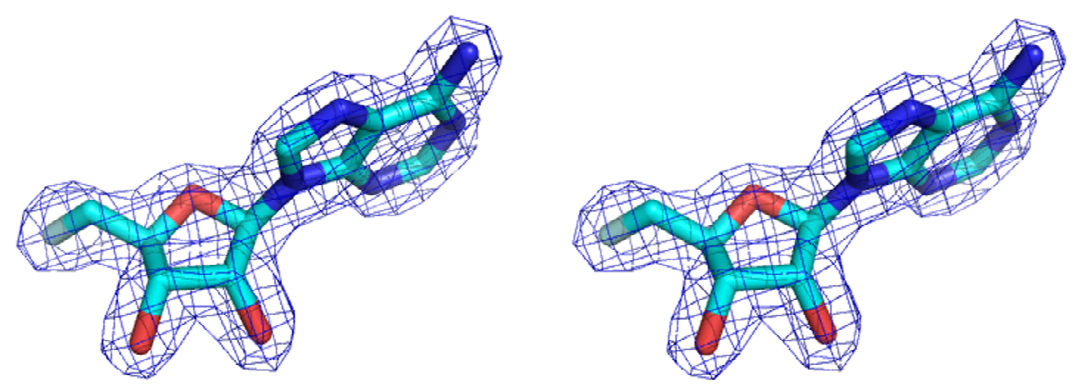

b FDAS binary complex with FDA
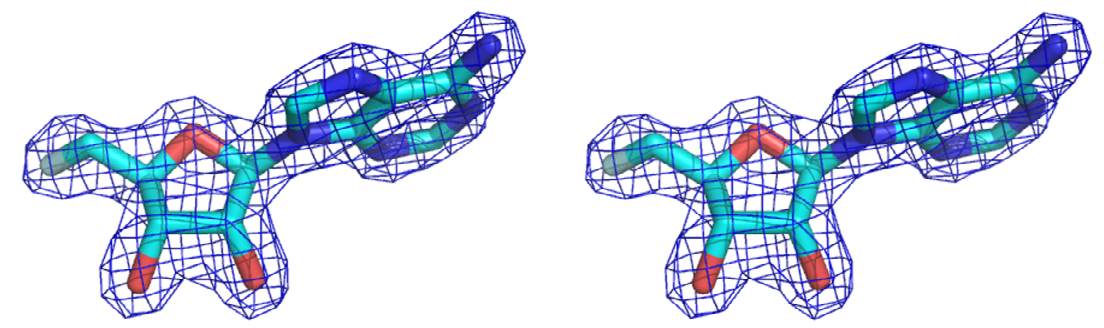

c S158G binary complex with FDA 

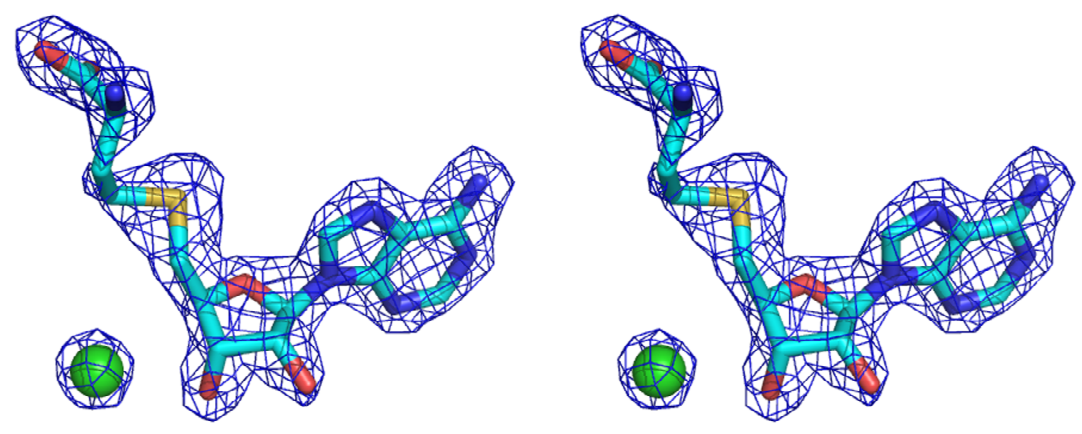

d S158G ternary complex with SAH and $\mathrm{Cl}^{-}(2 \mathrm{sig})$
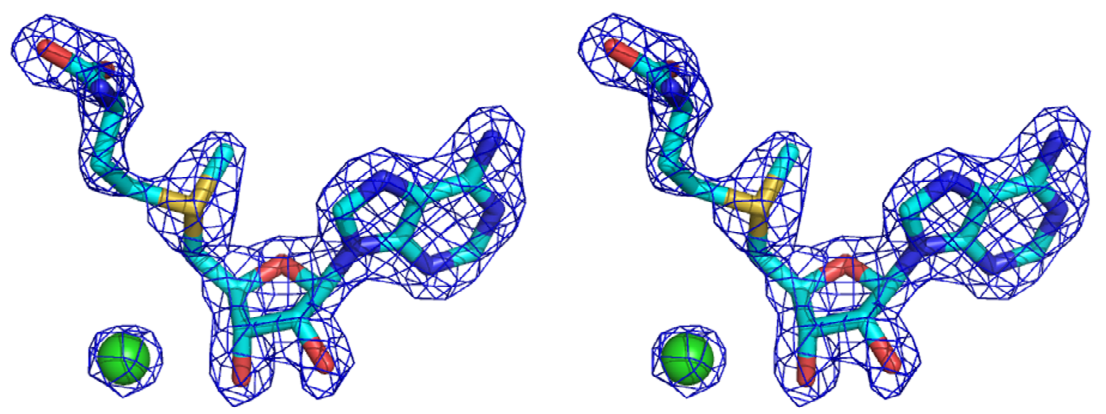

e S158G ternary complex with SAM and $\mathrm{Cl}^{-}$

Figure S5 The 2Fo-Fc map contoured at $1.5 \sigma$ in blue (otherwise indicated) for all ligands in the related structures. (a) S158A complex with FDA and L-Met; (b) wild type FDAS complex with FDA; (c) S158G complex with FDA; (d) S158G complex with SAH and $\mathrm{Cl}^{-}$(map was contoured at $2 \sigma$ around $\mathrm{Cl}^{-}$; (e) S158G complex with SAM and $\mathrm{Cl}^{-}$(map was contoured at $2 \sigma$ around $\mathrm{Cl}^{-}$). 
a

b

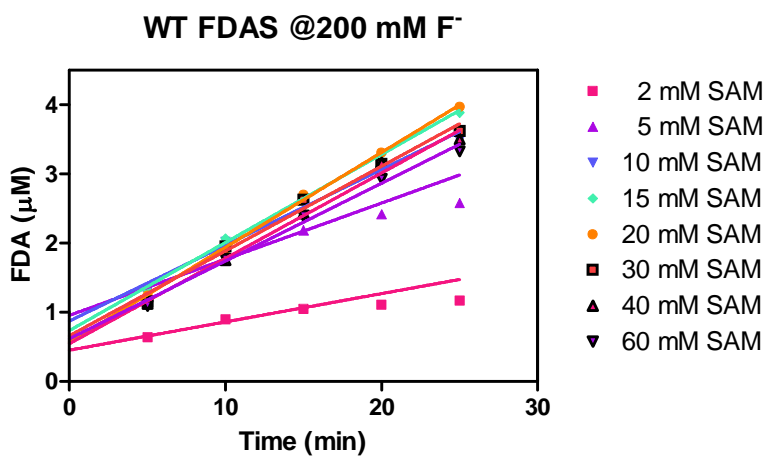

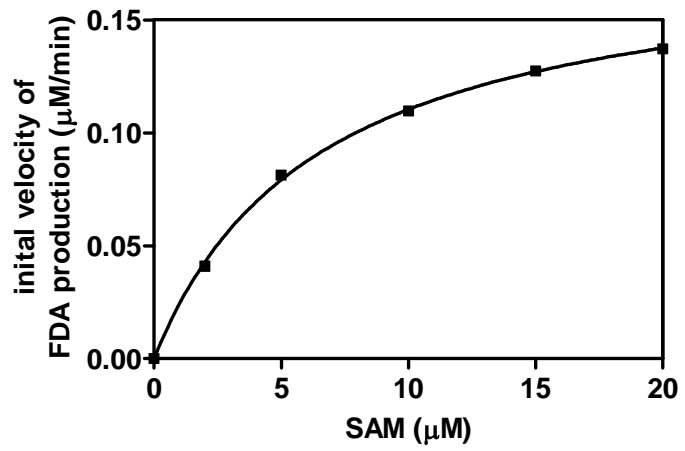

Figure S6 The steady state kinetic analysis of wild type FDAS as SAM is the variable substrate with the constant $\mathrm{F}^{-}$concentration of $200 \mathrm{mM}$. (a) The determinations of the initial velocities under the indicated SAM concentrations; (b) The calculation of the steady state kinetic parameters by fitting the initial velocities versus SAM concentration to the Michaelis-Menten equation without considering the data showing substrate inhibition. The kinetic parameters are summarized in Table 2.

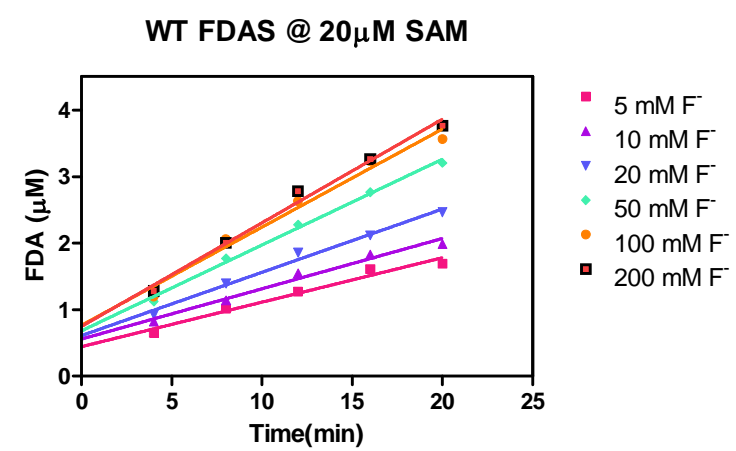

b

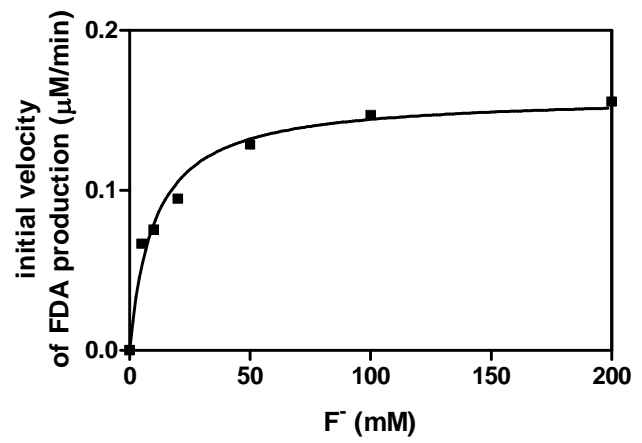

Figure S7 The steady state kinetic analysis of wild type FDAS as $\mathrm{F}^{-}$is the variable substrate with the constant SAM concentration of $20 \mu \mathrm{M}$. (a) The determinations of the initial velocities under the indicated $\mathrm{F}^{-}$ concentrations; (b) The calculation of the steady state kinetic parameters by fitting the initial velocities versus $\mathrm{F}^{-}$concentration to the Michaelis-Menten equation. The kinetic parameters are summarized in Table 2. 

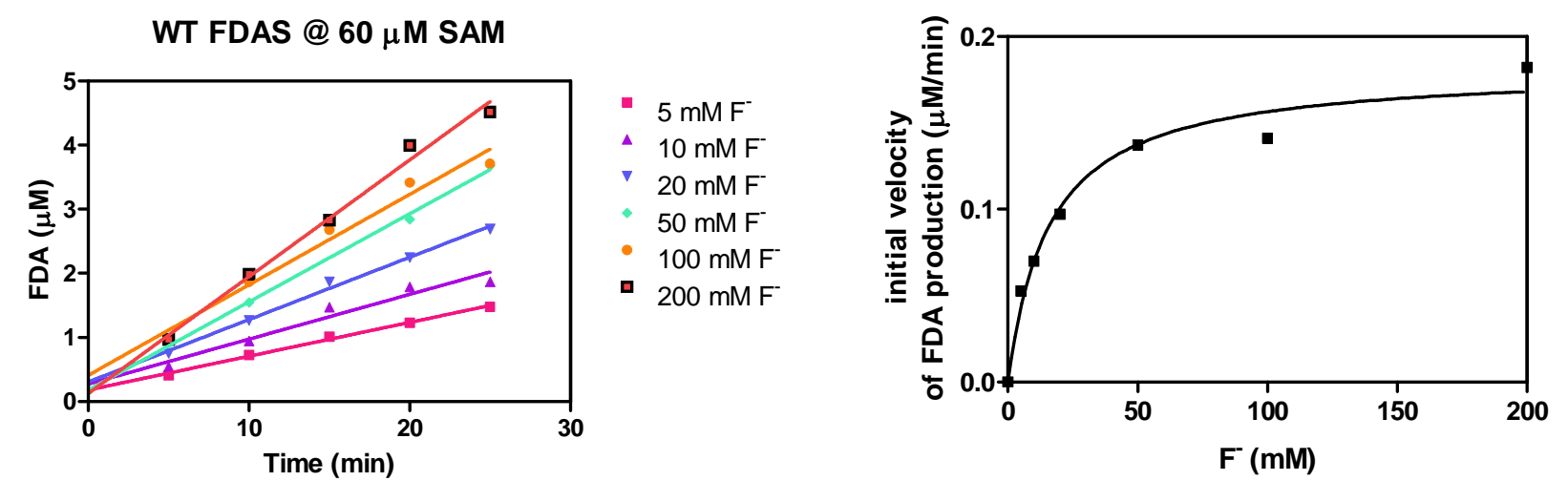

Figure S8 The steady state kinetic analysis of wild type FDAS as $\mathrm{F}^{-}$is the variable substrate with the constant SAM concentration of $60 \mu \mathrm{M}$. (a) The determinations of the initial velocities under the indicated $\mathrm{F}^{-}$ concentrations; (b) The calculation of the steady state kinetic parameters by fitting the initial velocities versus $\mathrm{F}^{-}$concentration to the Michaelis-Menten equation. The kinetic parameters are summarized in Table 2.

a

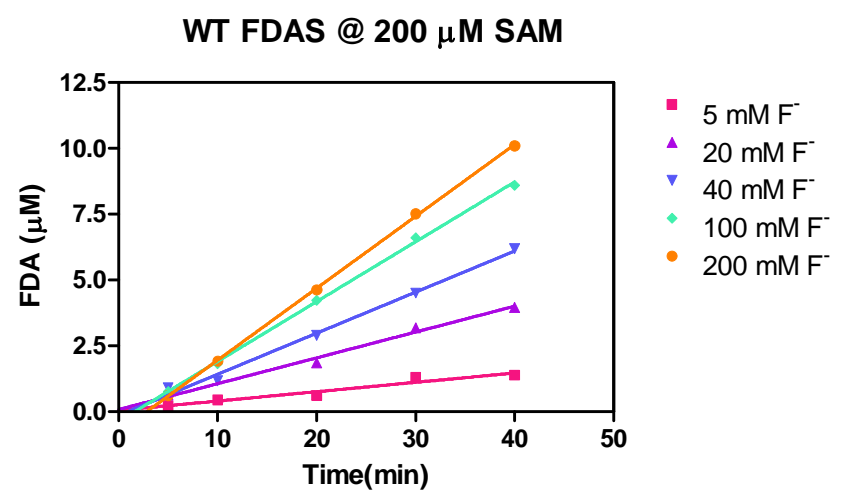

b

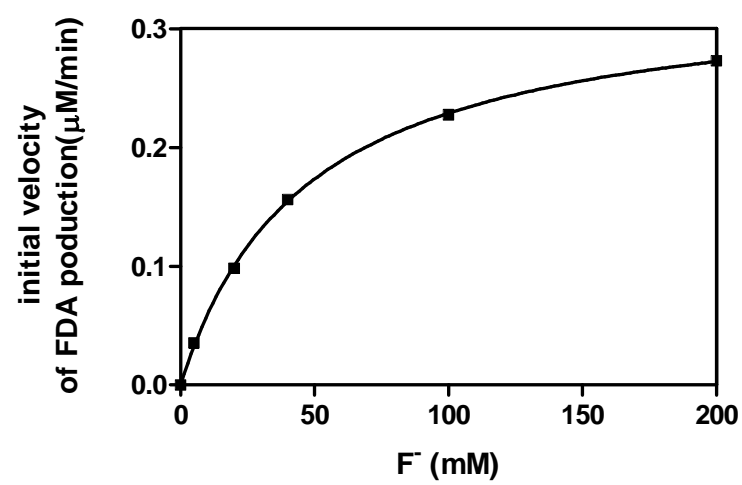

Figure S9 The steady state kinetic analysis of wild type FDAS as $\mathrm{F}^{-}$is the variable substrate with the constant SAM concentration of $200 \mu \mathrm{M}$. (a) The determinations of the initial velocities under the indicated $\mathrm{F}^{-}$ concentrations; (b) The calculation of the steady state kinetic parameters by fitting the initial velocities versus $\mathrm{F}^{-}$concentration to the Michaelis-Menten equation. The kinetic parameters are summarized in Table 2. 
a

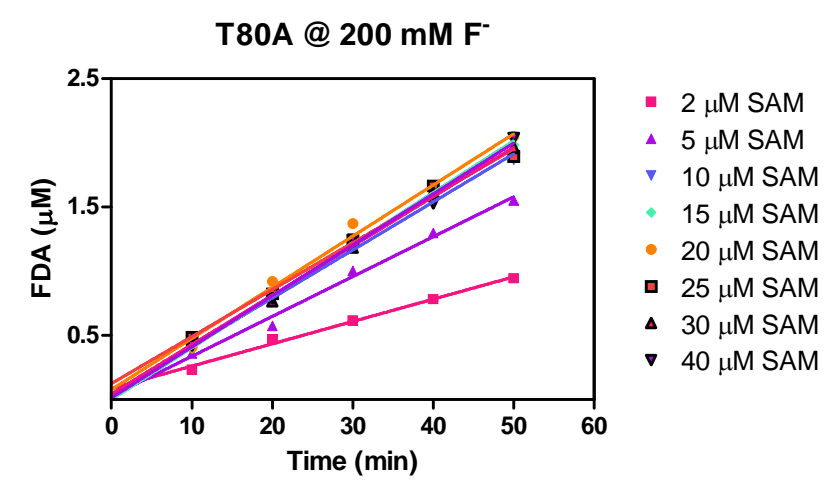

b

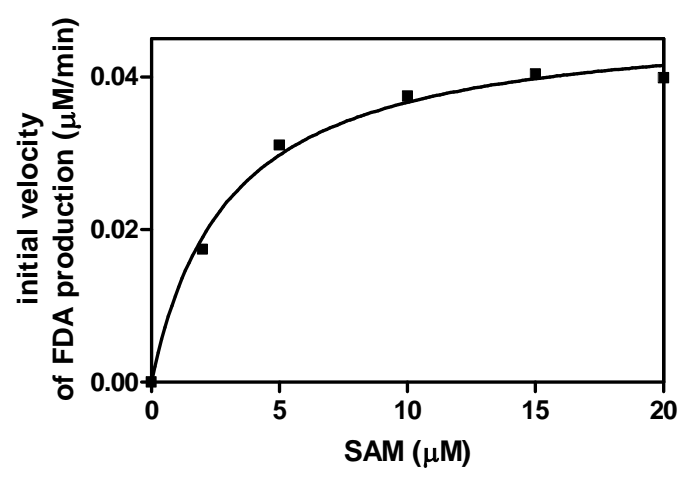

Figure S10 The steady state kinetic analysis of T80A as SAM is the variable substrate with the constant $\mathrm{F}^{-}$ concentration of $200 \mathrm{mM}$. (a) The determinations of the initial velocities under the indicated SAM concentrations; (b) The calculation of the steady state kinetic parameters by fitting the initial velocities versus SAM concentration to the Michaelis-Menten equation without considering the data showing substrate inhibition. The kinetic parameters are summarized in Table 2.

a

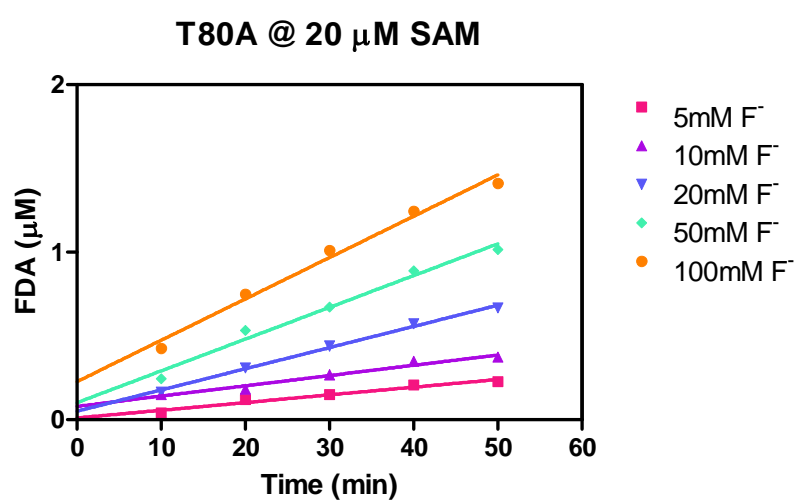

b

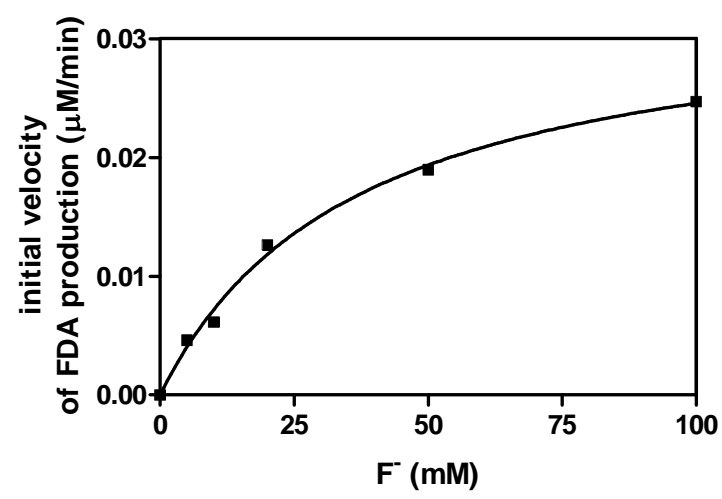

Figure S11 The steady state kinetic analysis of T80A as $\mathrm{F}^{-}$is the variable substrate with the constant SAM concentration of $20 \mu \mathrm{M}$. (a) The determinations of the initial velocities under the indicated $\mathrm{F}^{-}$concentrations; (b) The calculation of the steady state kinetic parameters by fitting the initial velocities versus $\mathrm{F}^{-}$concentration to the Michaelis-Menten equation. The kinetic parameters are summarized in Table 2. 
a

b

T80S@ 200 mM F-

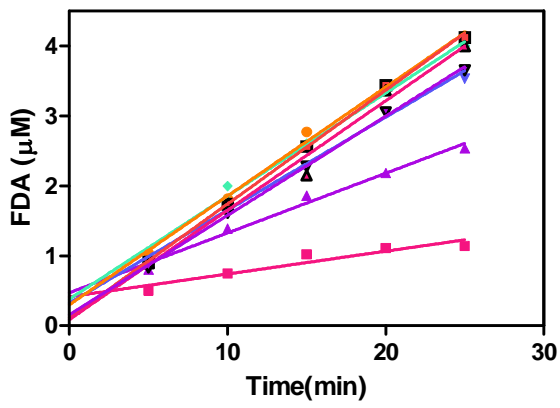

- $2 \mu \mathrm{M} \mathrm{SAM}$

- 5 MMSAM

$\checkmark 10 \mu \mathrm{MSAM}$

15 $1 \mathrm{M}$ SAM

- $20 \mu \mathrm{M}$ SAM

- $25 \mu \mathrm{M} \mathrm{SAM}$

\ $30 \mu \mathrm{M}$ SAM

จ $40 \mu \mathrm{M}$ SAM

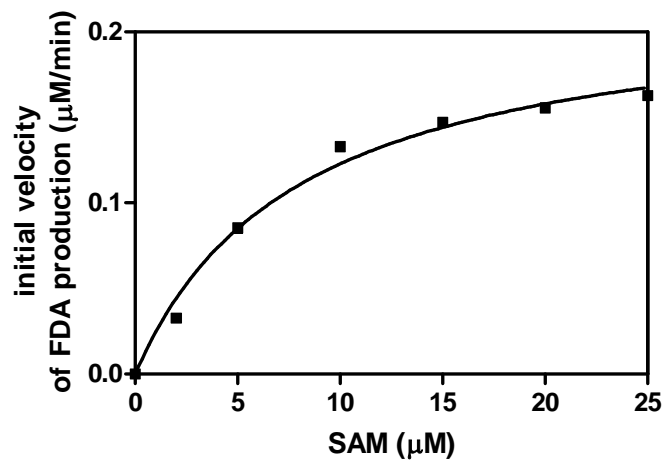

Figure S12 The steady state kinetic analysis of T80S as SAM is the variable substrate with the constant $\mathrm{F}^{-}$ concentration of $200 \mathrm{mM}$. (a) The determinations of the initial velocities under the indicated SAM concentrations; (b) The calculation of the steady state kinetic parameters by fitting the initial velocities versus SAM concentration to the Michaelis-Menten equation without considering the data showing substrate inhibition. The kinetic parameters are summarized in Table 2.

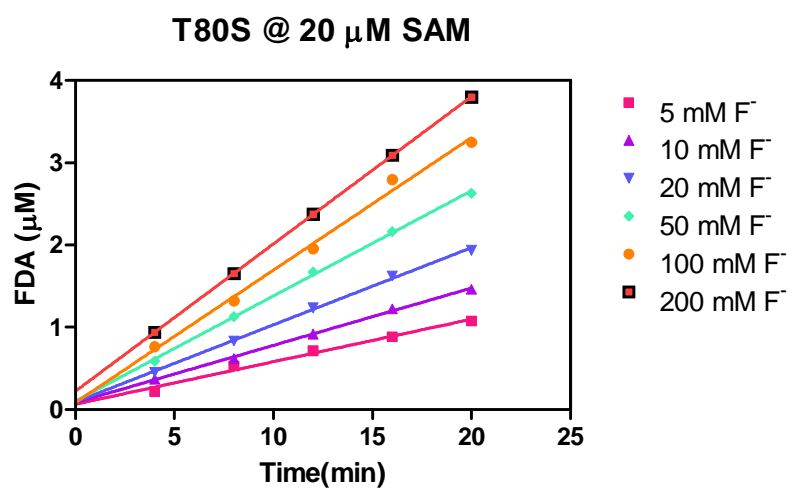

b

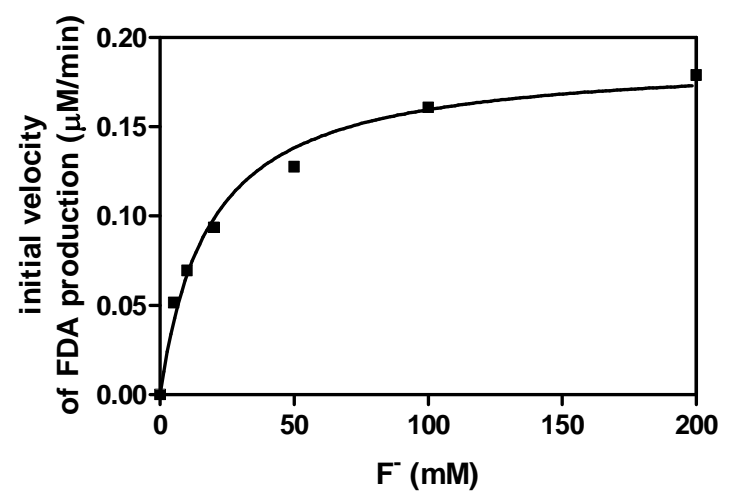

Figure S13 The steady state kinetic analysis of T80S as $\mathrm{F}^{-}$is the variable substrate with the constant SAM concentration of $20 \mu \mathrm{M}$. (a) The determinations of the initial velocities under the indicated $\mathrm{F}^{-}$concentrations; (b) The calculation of the steady state kinetic parameters by fitting the initial velocities versus $\mathrm{F}^{-}$concentration to the Michaelis-Menten equation. The kinetic parameters are summarized in Table 2. 

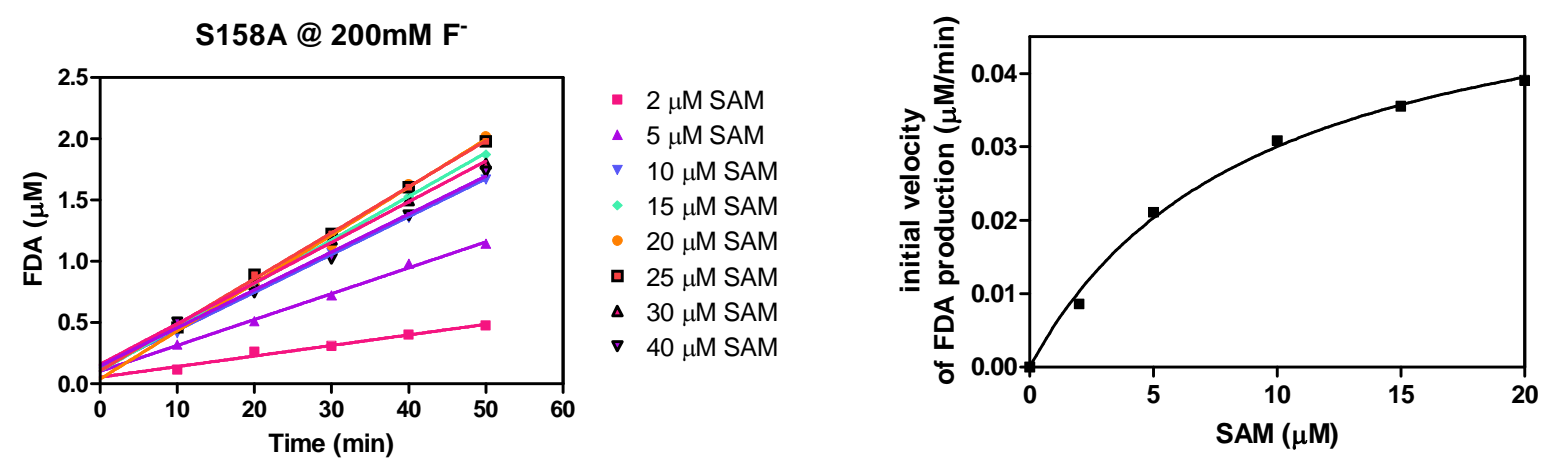

Figure S14 The steady state kinetic analysis of S158A as SAM is the variable substrate with the constant $\mathrm{F}^{-}$ concentration of $200 \mathrm{mM}$. (a) The determinations of the initial velocities under the indicated SAM concentrations; (b) The calculation of the steady state kinetic parameters by fitting the initial velocities versus SAM concentration to the Michaelis-Menten equation without considering the data showing substrate inhibition. The kinetic parameters are summarized in Table 2.

a

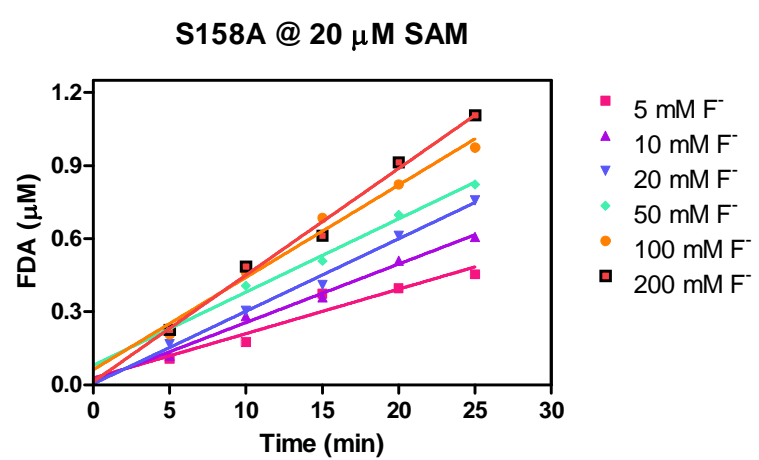

b

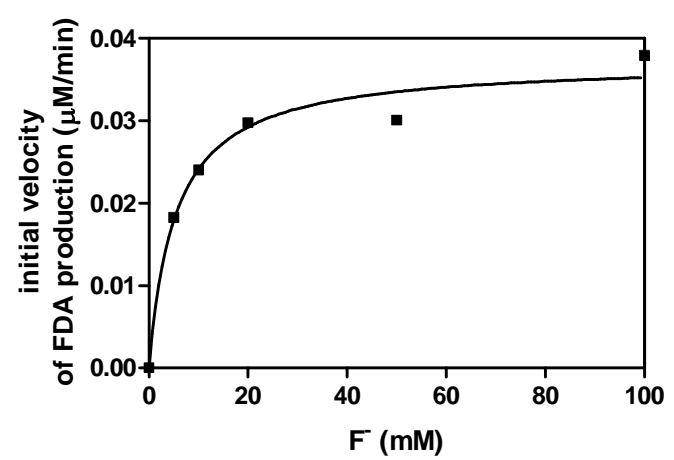

Figure S15 The steady state kinetic analysis of S158A as $\mathrm{F}^{-}$is the variable substrate with the constant SAM concentration of $20 \mu \mathrm{M}$. (a) The determinations of the initial velocities under the indicated $\mathrm{F}^{-}$concentrations; (b) The calculation of the steady state kinetic parameters by fitting the initial velocities versus $\mathrm{F}^{-}$concentration to the Michaelis-Menten equation. The kinetic parameters are summarized in Table 2. 
a

b

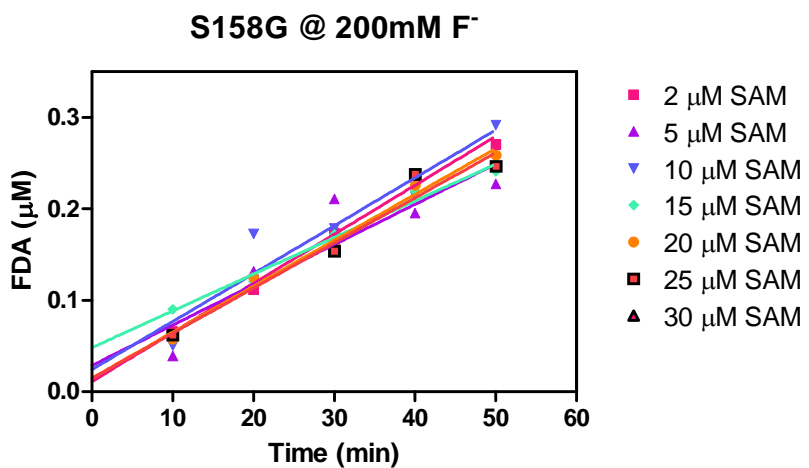

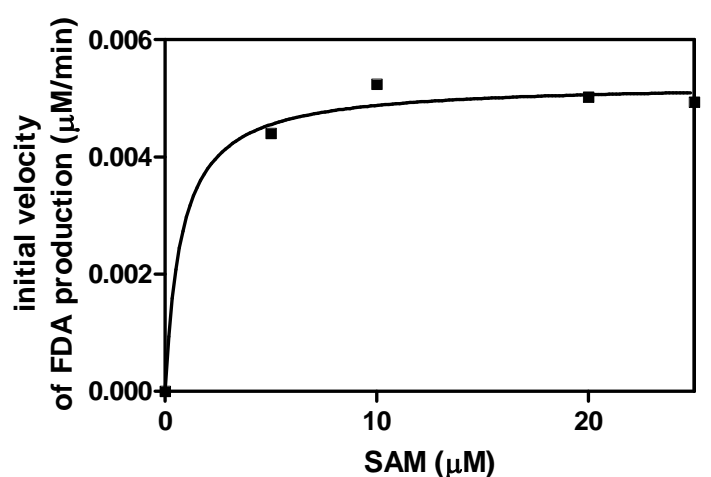

Figure S16 The steady state kinetic analysis of S158G as SAM is the variable substrate with the constant $\mathrm{F}^{-}$ concentration of $200 \mathrm{mM}$. (a) The determinations of the initial velocities under the indicated SAM concentrations; (b) The calculation of the steady state kinetic parameters by fitting the initial velocities versus SAM concentration to the Michaelis-Menten equation without considering the data showing substrate inhibition. The kinetic parameters are summarized in Table 2.

a

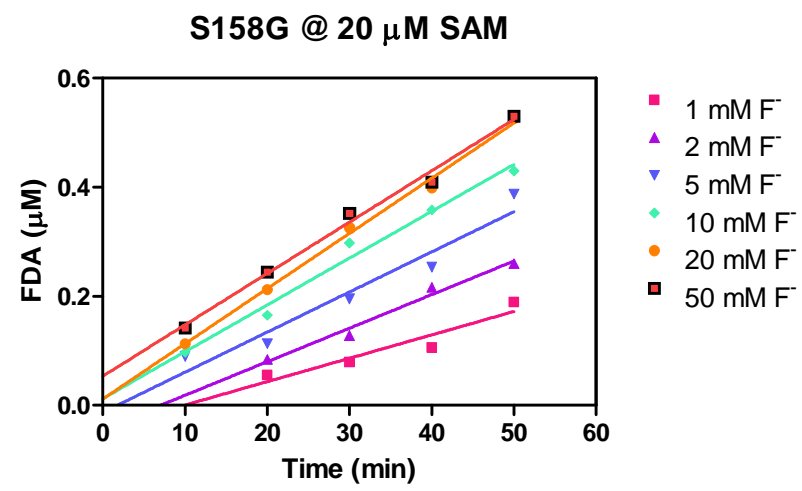

b

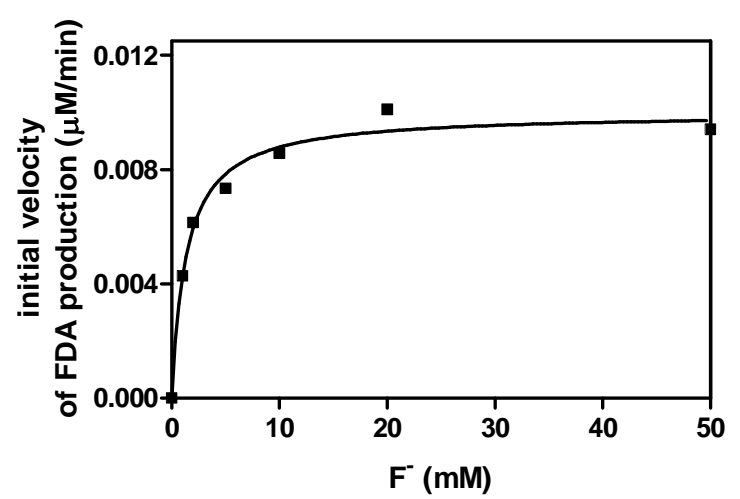

Figure S17 The steady state kinetic analysis of S158G as $\mathrm{F}^{-}$is the variable substrate with the constant SAM concentration of $20 \mu \mathrm{M}$. (a) The determinations of the initial velocities under the indicated $\mathrm{F}^{-}$concentrations; (b) The calculation of the steady state kinetic parameters by fitting the initial velocities versus $\mathrm{F}^{-}$concentration to the Michaelis-Menten equation. The kinetic parameters are summarized in Table 2. 